\title{
AN OPEN DROUGHT MONITORING SYSTEM FOR THE DEDURU OYA BASIN IN SRI LANKA IN THE CONTEXT OF THE 4ONSE PROJECT.
}

\author{
D. Strigaro ${ }^{1 *}$, M. Cannata ${ }^{1}$, E. Warusavitharana ${ }^{2}$, B.H. Sudantha ${ }^{3}$, R. Ratnayake ${ }^{2}$ \\ ${ }^{1}$ IST-DACD, University of Applied Sciences and Arts of Southern Switzerland (SUPSI), 6952 Canobbio, Switzerland \\ (daniele, massimiliano)@supsi.ch \\ ${ }^{2}$ Department of Town \& Country Planning, University of Moratuwa, 10400 Moratuwa, Sri Lanka (emeshi, rangajeewar)@uom.lk \\ ${ }^{3}$ Department of Information Technology, University of Moratuwa, 10400 Moratuwa, Sri Lanka (sudanthabh@uom.lk)
}

\section{Commission IV, WG IV/4}

KEY WORDS: 4onse, istSOS, Open Hardware, Open Software, Open Data, Environmental Monitoring System, Drought, SPI

\begin{abstract}
:
During the last decade, many climatic parameters are more and more deviating from the mean values calculated over historical climatic time-series. The World Meteorological Organization (WMO) stated that years 2015, 2016 and 2017 were the warmest since 1850. According to the preliminary data analysis of the last year, this trend is going to continue in 2018 as well. These climatic changes have accelerated the occurrence of droughts in many parts of the world including Europe and Asia. The North Western region is one such region in Sri Lanka which always affected by droughts due to its inherent dry weather condition. Although drought is considered as a normal part of the climate, its increasing negative impacts on human activities and the environment urges the application of novel technologies in drought monitoring. The 4onse project (analysis of Open, Non-conventional, Sustainable and Effective monitoring systems), funded by the Swiss National Science Foundation (SNSF), is a project began in this context to address the aforementioned mentioned issues by deploying 27 open technologies based Environmental Monitoring Systems (EMS) in Deduru Oya basin of Sri Lanka. These systems measure weather parameters such as temperature, humidity, pressure, rainfall, wind speed and wind direction. Thanks to the collected data, it was possible to calculate some drought indexes to evaluate the intensity of the dry periods. The Standard Precipitation Index (SPI) has been selected as the principal indicator to evaluate droughts by integrating the 4onse data together with Climate Hazards group Infrared Precipitation with Stations (CHIRPS) dataset.
\end{abstract}

\section{INTRODUCTION}

Monitoring environmental parameters is a key requirement to better understand the natural phenomena and to assess the status of the environment. To date, conventional weather observing networks play a significant role in providing timely data with the highest quality and resolution. This in-situ monitoring is fundamental to calibrate satellite-based weather data and to provide consistent weather data for hydrological and drought evaluation and analysis. However, due to lack of in-situ monitoring systems in developing and low-income countries, the globally distributed models developed by the technologically advanced countries are used to collect measurements on weather parameters and to assess climatic trends. Hence, for developing and low income countries, the data derived from the satellitebased weather algorithms are the only available means of collecting long term and up to date weather records, owing to the limitations of the data provided by the existing hydrometeorological network. In Sri Lanka, the meteorological data and water resources data are collected by five government agencies according to their own protocols. They are, Irrigation Department for hydro-meteorological data; Central Environmental Authority for water quality data; National Water Supply and Drainage Board for ground water data; Water Resources Board for groundwater data; and Meteorological Department for Climate data. The data are not integrated and shared among these agencies through web services and they are mainly available as hard copies. Thus, no open standards or database infrastructure is available at present. Since the data are not freely and publicly available, every time, the researchers and decision makers need to purchase data and required to undergo redundant data collection procedures. Further, the spatial distribution of the hydro-meteorological network in Sri Lanka is restricted to certain locations of the country due to high installation and maintenance cost, unavailability of local spare parts and technical knowledge to refurbish them during a break down. Most of them are manually operated and data are transmitted vocally over the phone once or two times per day. Hence, there is no automatic and user independent control on the accuracy, completeness, consistency, timeliness and coverage of the data. Even though the country has 37 Automatic Weather Stations (AWS) installed by different international funding agencies, most of them cannot be adjusted to integrate new parameters (Senevirathna, S. and Jayawickrama, V., 2014).

\subsection{The 4onse project}

The 4onse project (Four times Open Non-conventional system for Sensing the Environment), which is funded by the Swiss National Science Foundation (SNSF), tries to evaluate if a fully open solution can help developing and low-income countries to fill the existing gaps pertaining to environmental monitoring, with the developed countries. The general system architecture of the monitoring network was designed using Open Software, Open Standards, Open Hardware and Open Data. It is constituted of three main layers (Figure 1): the hardware layer is composed of sensor domain, it has the role of observing the environment and it is individuated by the wireless sensor network (WSN) nodes; the communication layer relies on the acquisition domain, which has the role of transferring data from the "field" to the "office"; the service layer composed of data management, processing and exploiting and characterized by a number of chained web services. Each layer was implemented and consequently tested and validated. Two main weather station solutions were developed (hardware layer). One is based on a Printed Circuit Board (PCB) (4onse-pcb) and the other is a modular solution fully composed of spare parts available in the market (4onse-mod). Both stations use Arduino as the main open hardware component and share same kind of sensors. The solution was compared with an official weather station of Canton Ticino and the results were very promising (Strigaro et al., 2019). The Sensor Observation Service (SOS) of the Open Geospatial Consortium was selected as the Open Standard to share the data and metadata collected by the stations. The software istSOS is 
the core component chosen for the service layer since it is fully compliant to the SOS version 1 and 2. In addition, it proved very good stability in the management of the hydro-meteorological network of the Canton Ticino in Switzerland (Cannata et al., 2013).

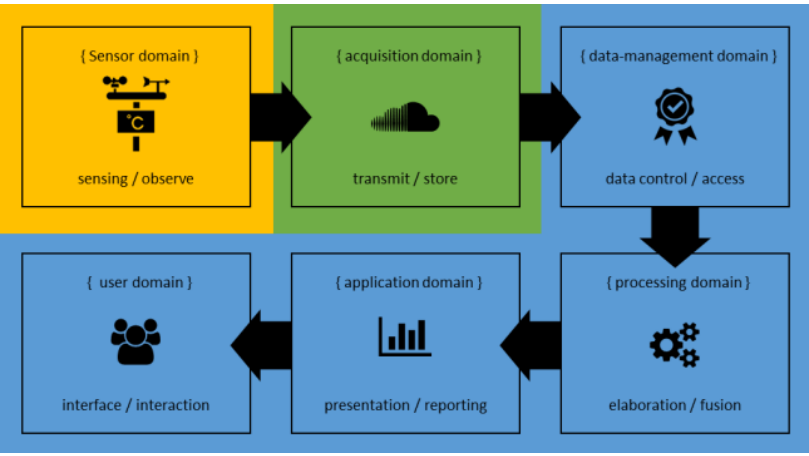

Figure 1. The 4onse monitoring architecture grouped in hardware (yellow), communication (green) and service layer

(blue).

The acquisition domain relies on a GPRS $2 \mathrm{G}$ connection between the stations and the istSOS which was optimized to decrease the energy and bandwidth consumption by increasing the affidability of the data transmission.

\subsection{The drought monitoring}

The data collected by the 4onse weather network is the basis to collect information about intense rainfall events and to identify drought hotspots. Once, the algorithm has been developed, it will be fully integrated in an automatic system to offer an early warning system based on the real-time data collected. A notification system can alert decision makers and stakeholders when a drought period is detected to better manage the water reservoirs and act in time to mitigate the adverse impacts to crops. Currently, the calculation of drought is an open topic since there is still not a shared and accepted procedure. However, many scholars in world-wide have developed indexes and indicators for detecting dry or wet periods (Heim, 2002, Mishra and Sing, 2010). The common parameters used by most of them are rainfall and the temperature observations which, therefore, are collected by the 4onse network. The development of the drought monitoring system will give an additional result to prove whether a fully open system can be a viable alternative to more conventional solutions.

\section{Materials ANd Methods}

\subsection{The study area}

The study area selected is the Deduru Oya river basin of Sri Lanka. It has a catchment area of about $2687 \mathrm{~km}^{2}$. It is located within the highly vulnerable areas due to climate change according to recent studies (Katupotha, 2009). As illustrated in Figure 2, the basin area falls under two climatic zones, wet and intermediate. $97 \%$ of the basin area is covered by the North Western Province (Kurunegala and Puttalam Districts) and 3\% by the Central Province (Kandy and Matale Districts).

The existing weather station network of Deduru Oya river basin consists of several stations belong to Meteorological Department and Irrigation Department (Figure 3). In addition, the Bathalagoda rice research institute has certain weather monitoring devices at their premises. The regional stations of the Meteorological Department collect parameters related to rainfall, temperature and relative humidity on a daily basis and the parameters related to solar radiation and wind speed are collected on monthly and annual basis respectively. The stations belong to Irrigation Department mainly collect rainfall and water level measurements. Most of these stations are manually operated and the data is not freely available in digital format.

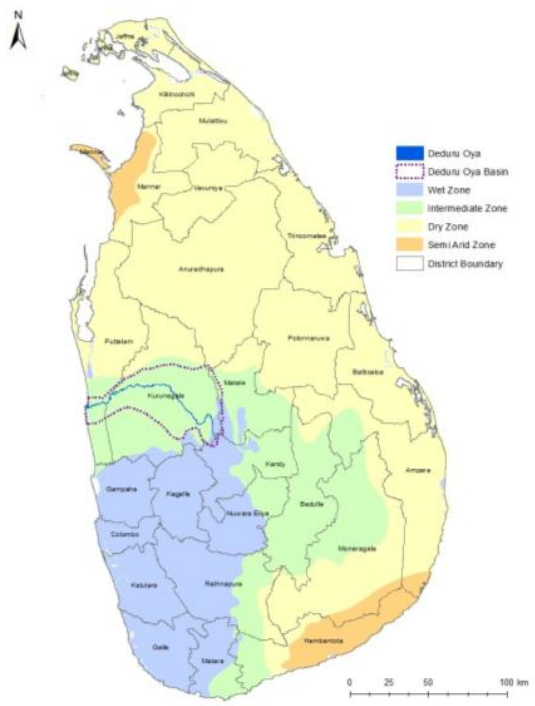

Figure 2. Climatic zones of Sri Lanka and the location of Deduru Oya basin

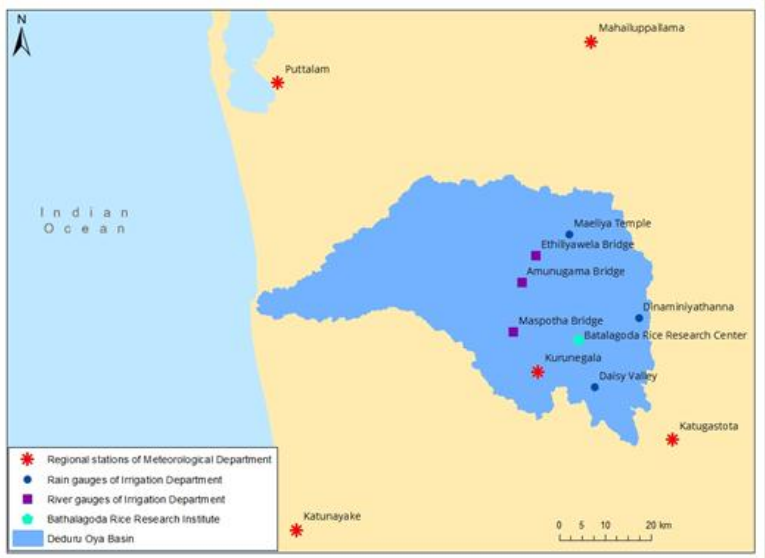

Figure 3. The existing hydrometeorological network of Deduru Oya basin

\subsection{The 4onse stations deployment}

During the second year of the project, twenty-seven 4onse stations were installed in the Deduru Oya basin. The stations collect observations related to rainfall, temperature, pressure, relative humidity, solar radiation, wind speed and wind direction every 10 minutes. Additionally, six river gauges have been installed in the basin to obtain river level measurements that will be used for the development of a hydrological model for flood management (Figure 4).

The location identification for the 4onse stations was commenced under the constraint of no prior information on hydrometeorological condition and the setting of the river basin is available. Hence, as the foremost step, the boundary and the subbasins of the watershed were delineated using SWAT (Soil and Water Assessment Tool) hydrological modelling tool. The selection of locations for the stations was performed through a 
geostatistical analysis of satellite-based rainfall data and several other factors were also considered in site selection (Warusavitharana, et.al, 2018). Accordingly, the following factors were considered in determining the number and final locations for the 4onse stations:

- Consideration of areas with high rainfall entropy values

- Deployment of at least one station in each sub-basin in proximity to its centroid

- Accessibility - availability of good road network to reach to the stations

- Signal strength

- Security - government or public places with security officers

- Availability of open spaces

- More than $100 \mathrm{~m}$ away from water bodies

- Areas with no effects from shadows of buildings and trees when the sun is higher than $5^{0}$

- Availability of flat land

Out of the six river gauges, five of them were installed in the upper basin area and the remaining one was installed at the lower basin closer to the Deduru Oya reservoir. Figure 5 shows the locations of the twenty seven 4onse weather stations and the six river gauges installed in the Deduru Oya basin.

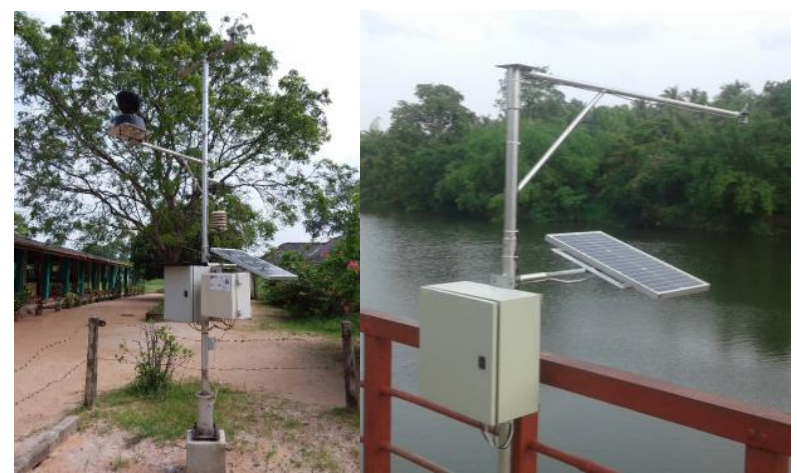

Figure 4. On the left 4onse-mod station deployed in Kubukgete Central College (SL); On the right river gauge installed in Ridie Bandi Ella (SL)

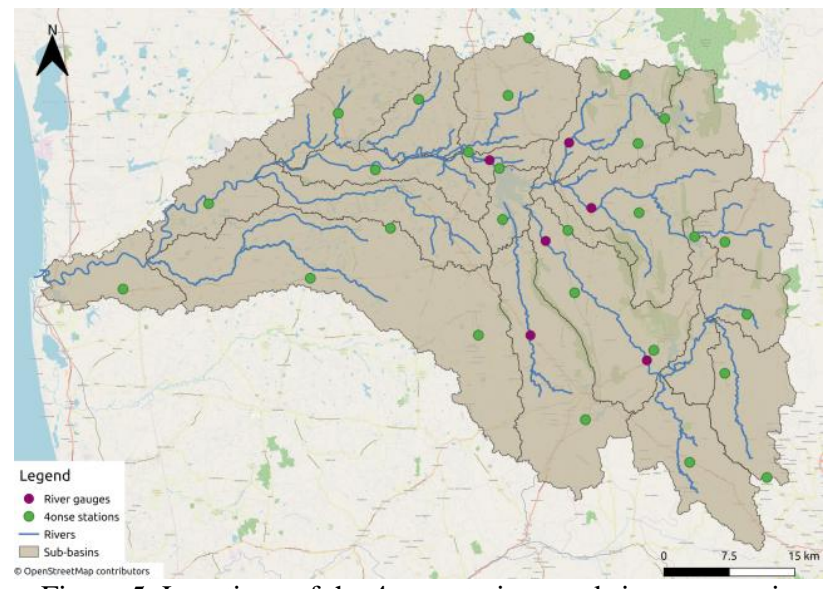

Figure 5. Locations of the 4onse stations and river gauges in Deduru Oya basin

\subsection{Standard Precipitation Index (SPI)}

The Standard Precipitation Index (SPI) (McKee at al., 1993) is a statistical index that uses historical time series of almost 30 years to represent and detect abnormal wet or dry periods.
According to the Lincoln Declaration on Drought Indices (LDDI) approved by the World Meteorological Office (WMO), the SPI is recommended as a principal indicator to use around the world for characterizing the meteorological drought. It requires only precipitation parameter for calculation and provides results that can be compared across different climatic conditions. Usually, it is calculated with different temporal window intervals ranging from 1 to 36 months, fitting the daily or monthly precipitation values with a gamma or a Pearson Type III distribution. In the context of the presented work, a SPI with a temporal window of 30 days is calculated using daily accumulated precipitation values and a Pearson Type III distribution (Guttman 1998 and 1999). Since the 4onse stations do not provide historical time series of almost 30 years, the CHIRPS satellite dataset was chosen and merged to the rainfall dataset of the stations.

To this end, the climate_indices open source python library developed and maintained by NIDIS/NCEI/NOAA was selected to perform the calculation of the SPI. The library permits to calculate various climate indexes to provide a picture of the severity of precipitation and temperature anomalies useful for climate monitoring and research.

\subsection{The software architecture}

The script for the SPI calculation was developed taking advantage of the Jupyter Lab (https://jupyterlab.readthedocs.io) which is implemented upon the Project Jupyter (https://jupyter.org/). It is a web-based developing platform oriented in particular to scientists in order to get open-source software and interactive computing across dozens of programming languages. For the purpose of this work, we used a Python 3 kernel for implementing a notebook which is easily shareable and commented through the MarkDown language that is fully supported. Jupyter Lab comes out with many scientific library already installed like pandas (https://pandas.pydata.org/) for time-series manipulation.

The algorithm starts using the GetCapabilies to retrieve the basic information for each station. Then, the DescribeSensor permits to get per each station the sampling time frequency, the coordinates and the observed properties. The next step concerns the retrieve of the observations with the GetObservations function using a filter on the observed property since only the rainfall is expected to be used for SPI. Thus, thanks to the istSOS SOS standard, all the metadata and rainfall data for each sensor were processed and filtered according to the requirements. Successively, the CHIRPS dataset composed by NetCDF files automatically downloaded and updated from the NCDA repository, was used for filling the time-series to the end of obtaining a 30 years daily rainfall series per stations. Once the SPI with a 30 days window was elaborated plots per each station were automatically created using the matplotlib python library (https://matplotlib.org/) (Figure 6).

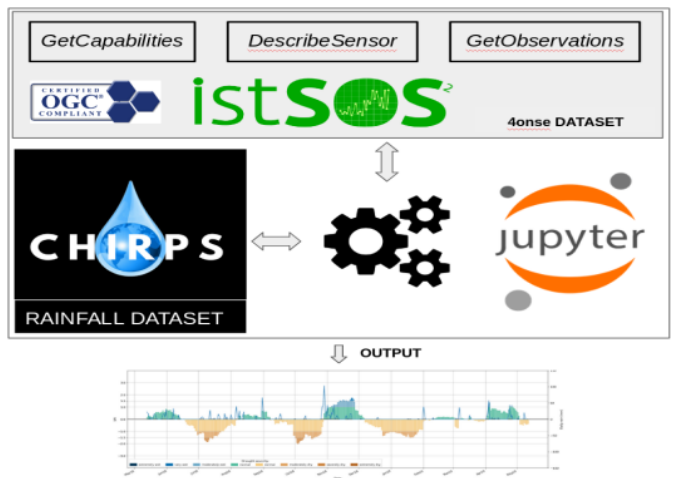

Figure 6. Algorithm for the SPI calculation. 


\section{Results And Conclusions}

In Figure 7, the preliminary results of the procedure described in the previous paragraph is shown. The SPI with a 30 days temporal window was calculated. The analysis showed three main drought events. The first (D01) occured in the second half of August 2018. The second (D02) spanned from the beginning of December 2018 until the end March 2019. The last (D03) is currently affecting the area with SPI values classified as severely dry conditions.

Considering the technologies involved, the presented paper showed a fully open approach applied in the development of a prototype procedure for the implementation of a drought monitoring system in the context of the 4onse project.

The istSOS with the SOS standard guaranteed a high interoperability of the metadata and the data collected by the installed 4onse monitoring network. Since the starting date of deployment of an open weather station based on Arduino, 27 stations have been deployed in the Deduru Oya basin of Sri Lanka. The stations collect the basic environmental parameters like temperature, humidity, pressure and rain continuously. Such real-time data are transmitted to the istSOS data management system and shared through the SOS standard. The openness approach used, permits to utilize not only the software, but also the data and the hardware domains in the public as well as private sectors. The proposed methodology demonstrated that from such a kind of open system, it is possible to implement elaborations to monitor hazardous phenomena. The algorithm proposed for the SPI calculation will be further developed to offer a web based system where drought or wet conditions are monitored in realtime. In addition, a notification service could be built up to alert decision makers and stakeholders in taking mitigation actions in time.

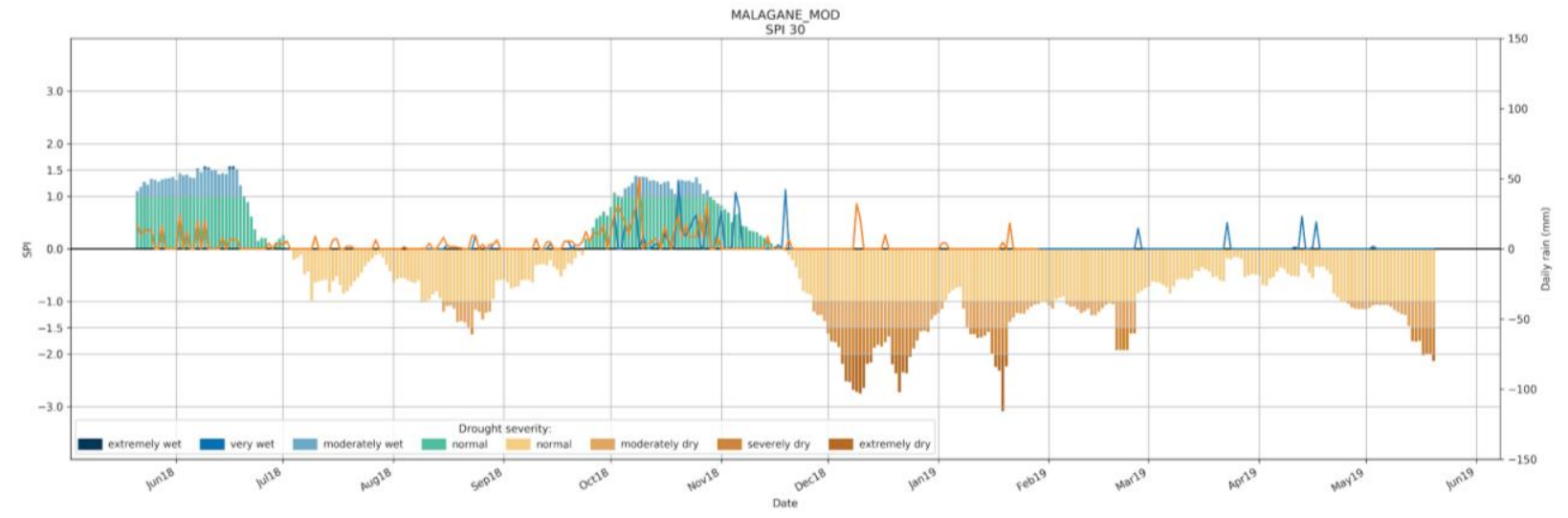

Figure 7. The SPI 30 calculated for the Malagane station for the last 365 days plus CHIRPS dataset (line orange) and Malagane station dataset (line blue)

\section{REFERENCES}

Cannata, M., Antonovic, M., Molinari, M., \& Pozzoni, M. (2013). ISTOS, sensor observation management system: a real case application of hydro-meteorological data for flood protection. International Archives of the Photogrammetry Remote Sensing and Spatial Information Sciences, 5, W3.

Guo, H., Bao, A., Liu, T., Ndayisaba, F., Jiang, L., Kurban, A., \& De Maeyer, P. (2018). Spatial and temporal characteristics of droughts in Central Asia during 1966-2015. Science of the total environment, 624, 1523-1538.

Guttman, N. B. (1998). Comparing the palmer drought index and the standardized precipitation index1. JAWRA Journal of the American Water Resources Association, 34(1), 113-121.

Guttman, N. B. (1999). Accepting the standardized precipitation index: a calculation algorithm 1. JAWRA Journal of the American Water Resources Association, 35(2), 311-322.

Heim Jr, R. R. (2002). A review of twentieth-century drought indices used in the United States. Bulletin of the American Meteorological Society, 83(8), 1149-1165.
Katupotha, J. (2009). Water shortage in lower Deduru oya Basin, National Conference in Water, Food Security and Climate Change, Sri Lanka.

McKee, T. B., Doesken, N. J., \& Kleist, J. (1993, January). The relationship of drought frequency and duration to time scales. In Proceedings of the 8th Conference on Applied Climatology (Vol. 17, No. 22, pp. 179-183). Boston, MA: American Meteorological Society.

Mishra, A. K., \& Singh, V. P. (2010). A review of drought concepts. Journal of Hydrology, 391(1), 202-216.

Senevirathna, S., \& Jayawickrama, A. (2014). Developing a National Climate Observatory System for Sri Lanka. Coordinating Secretariat for Science Technology \& Innovation.

Spinoni, J., Vogt, J. V., Naumann, G., Barbosa, P., \& Dosio, A. (2018). Will drought events become more frequent and severe in Europe?. International Journal of Climatology, 38(4), 1718-1736.

Strigaro, D., Cannata, M., \& Antonovic, M. (2019). Boosting a Weather Monitoring System in Low Income Economies Using Open and Non-Conventional Systems: Data Quality Analysis. Sensors, 19(5), 1185. 
WMO WMO statement on the state of the global climate in 2017; 2018; ISBN 978-92-63-11212-5.

Warusavitharana, E., Ratnayake, R., Mahanama, S. and Cannata, M. (2018). An approach to determine the optimum spatial distribution of hydrometeorological stations for hydrological modelling: 4ONSE deployment. In Proceedings of the $39^{\text {th }}$ Asian Conference on Remote Sensing (ACRS 2018). 15 - 19 October, Kuala Lumpur, Malaysia. 